\title{
ENSAIO SOBRE ALGUMAS RAÍZES PROFUNDAS DA CONTABILIDADE, EM APOIO AOS PRINCÍPIOS FUNDAMENTAIS
}

\section{ESSAY ABOUT SOME ACCOUNTING DEEP ROOTS, IN SUPPORT OF THE FUNDAMENTAL PRINCIPLES}

\author{
SÉRGIO DE IUDICIBUS \\ Professor Emérito da Faculdade de Economia, Administração e \\ Contabilidade da Universidade de São Paulo. \\ Professor do Mestrado em Contabilidade da Universidade Pontifícia Católica/SP \\ E-mail: siudicibus@osite.com.br
}

\section{Resumo}

O objetivo deste artigo é apresentar um ensaio teórico sobre os principais fundamentos da Contabilidade, assim traduzidos como raízes dessa ciência. De forma específica, busca-se uma reflexão histórico-crítica sobre o "Status Quo" da Contabilidade, tanto no âmbito nacional, quanto no internacional. Tendo em vista que alguns reguladores $e$ normatizadores consideram aceitar como base conceitual quase que única acabada e profunda da teoria contábil o conjunto de princípios fundamentais, esses sejam extremamente importantes para nortear as normas que suportam a prática contábil. Como produtos da pesquisa, destacam-se quatros grandes raízes: a primeira delas caracterizou pela análise da prevalência da essência sobre a forma; a segunda contevese na discussão da prevalência do todo sobre o individual; a terceira contemplou a prevalência da alocação sobre a valoração, e a prevalência da evolução sobre o "Status Quo" da contabilidade.

Palavras-chave: Teoria da Contabilidade; raízes da Contabilidade; essência sobre a forma; princípios fundamentais.

\begin{abstract}
The objective of this paper is to present a theoretical essay about the main accounting fundaments, translated as accounting roots. Specifically, it was aimed to historically and critically observe accounting status quo, either in national and international scenarios. Considering that some regulators and normalizers take the set of accounting theory fundamental principles as nearly the single, complete, and deep conceptual basis, although they are very important to rule and support accounting practice. The principles are emblematic and its study is indispensible. As results of this research, four large roots are highlighted: the first one of them was characterized by the analysis of the prevalence of substance over form; the second one embraced the discussion about the prevalence of the collective over the individual; the third contemplated the prevalence of allocation over value, and the last one focused the evolution of accounting status quo.
\end{abstract}

Key words: Accounting Theory, accounting roots, substance over form, fundamental principles. 


\section{INTRODUÇÃO}

O estudo dos "princípios fundamentais de contabilidade" (já denominados “princípios contábeis geralmente aceitos" e por ludicibus (1966) classificada em três níveis hierárquicos: postulados, princípios e convenções) tem sido uma das bases de pesquisas, palestras, aulas e interações com os discentes durante há de 45 anos de magistério, considerando uns 30 exclusivamente dedicados ao ensino de pós-graduação, nível de mestrado e doutorado.

De certa forma, é no mínimo estranho constatar que alguns reguladores e normatizadores aceitem como base conceitual quase única, acabada e profunda da Teoria Contábil, o conjunto de "princípios fundamentais" (na terminologia do Conselho Federal de Contabilidade - CFC), embora ele seja extremamente importante para nortear as normas que suportam a prática contábil. É evidente que a Teoria Contábil vai muito além dos "princípios" e envolve o tratamento de ativos, passivos, patrimônio líquido, intangíveis, qualidades da informação contábil e forma e conteúdo das demonstrações contábeis, além do estudo das várias abordagens teóricas e das novas tendências de teorias positiva, institucional e sociológica. Um vasto campo, então. Os "princípios fundamentais", todavia, são reconhecidamente emblemáticos e o seu estudo é essencial.

Certamente, as várias listagens de "princípios", em seu sentido histórico, não foram as mais adequadas para o estabelecimento de uma sólida base conceitual para a Teoria Contábil e, em conseqüência, para a própria contabilidade. É que, no fundo, elas se desenvolveram como resultado da crise da Bolsa de Nova lorque, em 1929, em que se exigiu das demonstrações contábeis um mínimo de fidedignidade. O famoso Comitê May (Comissão Especial de Cooperação com as Bolsas de Valores, sob a direção de George 0 . May, então presidente do AIA - American Institute of Accountants), em 1933, introduziu a obrigatoriedade do parecer de auditores independentes para as empresas que requeriam registro na Bolsa de Nova lorque, na base da aderência às práticas geralmente aceitas de contabilidade. (Na verdade, os ingleses já faziam essa exigência muito antes). Por outro lado, Paton havia escrito (1922) um livro de Teoria Contábil no qual lançava bases para os princípios fundamentais. De 1933 em diante multiplicaram-se os estudos e pronunciamentos dos órgãos de vários países sobre esse tal conjunto de "princípios fundamentais", culminando com as estruturas conceituais básicas dos órgãos internacionais FASB - Finance Accounting Standers Boards e IASB - International Accounting Standers Boards; e nacionais CFC - Conselho Federal de Contabilidade, CVM - Comissão de Valores Mobiliários, IBRACON - Instituto Brasileiro dos Auditores entre outros.

Embora esse trabalho de praticamente um século na busca de um corpo de princípios tenha evoluído bastante, atendendo aos reclamos emergenciais da sociedade com relação à qualidade das demonstrações contábeis, visto sua importância para a economia dos países; esse caráter emergencial subtraiu-lhe, às vezes, a ponderação e a pesquisa profundas sobre suas bases conceituais.

Eventualmente, os professores universitários de Contabilidade do início do século XX sentiam-se em desvantagem com relação aos colegas que ensinavam Economia. Como justificar o ensino da Contabilidade em nível superior explicando apenas débito e crédito, balancetes e demais demonstrações contábeis? Pareceu-lhes muito mais "nobre" iniciar o ensino pelos "princípios geralmente aceitos".

Diga-se, na verdade, que principalmente no início de sua evolução, tal conjunto de princípios pouco mais era do que um inventário de práticas contábeis promovidas por grandes empresas e grupos empresariais e apoiadas por auditores independentes.

Um aspecto muito interessante da questão é que o estudo dos princípios é uma tradição puramente anglo-saxônica. Os autores europeus de Teoria Contábil nunca se preocuparam em demasia com esse assunto, ou não se preocuparam absolutamente. As 
bases conceituais que eles, principalmente os italianos e alemães, debatiam eram outras, dependendo da "escola" de pensamento em moda a cada época. A discussão versava mais sobre a teoria das contas ou, nos casos mais avançados, na delimitação da função contábil, num campo mais amplo que seria a economia aziendal (economia empresarial).

Este trabalho, em forma de ensaio, livre de considerações formais, se deterá sobre os argumentos, conceitos básicos, fundamentos e outras considerações que facilitem o entendimento da estrutura teórica da Contabilidade. Existem raízes que não podem ser observadas à primeira vista e que formam a base de todo o edifício contábil (um pouco analogamente aos fatores intangíveis que são as raízes da árvore - balanço - em que quase só figuram-se itens tangíveis e os intangíveis adquiridos). Entretanto, as raízes profundas da Teoria Contábil são muito mais abrangentes, pois formam sua base conceitual, comportamental e filosófica, principalmente, para dar suporte aos "princípios".

No desenvolvimento do trabalho, foram abordados assuntos relacionados à teoria contábil, teorias normativa e positiva, bem como referências aos Princípios Fundamentais de Contabilidade. Tais alusões aos assuntos foram feitas esporadicamente, mas não obrigatoriamente.

Espera-se que este estudo, embora sucinto, agrade os estudantes de Teoria da Contabilidade em todos seus níveis, desde apreciadores da teoria e profissionais que gostam de ir além da superfície de seus problemas contábeis a reguladores contábeis.

Todavia, o assunto requer um aprofundamento posterior. Neste artigo, lançam-se apenas as primeiras considerações de caráter exploratório e limitações óbvias. Inclusive, numa reflexão posterior, outras raízes poderão ser identificadas e, se o assunto provocar discussão e análise, o trabalho deverá ser ampliado na perspectiva, até, de se editar um livro, futuramente.

Também, não se pretende redefinir a ciência contábil. Da mesma forma que a Economia é a ciência da escassez, a Contabilidade continua sendo a ciência do patrimônio (e, portanto, da escassez).

As raízes que timidamente se criam, apenas servem para um melhor entendimento o conjunto dos princípios fundamentais da Contabilidade.

\section{PREVALÊNCIA DA ESSÊNCIA SOBRE A FORMA: A PRIMEIRA GRANDE RAIZ}

Trata-se da primeira raiz profunda da Contabilidade e de sua teoria. Apresentada, usualmente, de forma vaga ou em classificação "ao Limbo", essa importante raiz, ou précondição na verdade, forma a base da Contabilidade moderna. Os grandes estudiosos de todos os tempos talvez não se utilizassem ou não conhecessem a expressão, mas certamente, alguns tinham consciência dela. Chambers (1961), por exemplo, demonstra essa consciência ao classificar como ativos apenas aqueles que possuem valor de troca (de mercado).

Aqui, é necessário lembrar que a importância da "forma" varia de acordo com as instituições jurídicas, crenças e valores de cada região ou país. Países cujas leis estão baseadas no direito romano tendem, via de regra, a dar maior importância à "forma jurídica", muitas vezes em preferência à "essência econômica". Portanto, existem outros fatores que "torcem" em favor da forma, como excessivo zelo pela objetividade, conservadorismo e falta de conhecimentos básicos de Economia.

Foram as estruturas conceituais de origem Anglo (exemplo: IASB), mais do que os tratadistas teóricos, a revelar a importância da essência econômica. No Brasil, a Estrutura Conceitual Básica da Contabilidade da CVM/ IBRACON assumiu de forma clara e concisa essa raiz da Contabilidade, colocando-a como pré-requisito. Ela não poderia ser classificada como postulado ambiental, pois transcende à Contabilidade, podendo ser apanágio de outras ciências, como Direito, Economia e Administração. Mas, certamente, a 
prevalência da essência sobre a forma nunca poderia ser um postulado jurídico, por exemplo. Ela é estritamente contábil, na "forma" de seu enunciado e aplicação, com conteúdo econômico e gerencial.

A prevalência da essência sobre a forma, todavia, provoca sérios problemas para os contadores acomodados, acostumados às regrinhas do custo, da objetividade extremada, treinados mais para obedecer às normas do que para serem criativos.

A "forma", além de ser de aplicação mais fácil nas culturas de direito romano, ainda leva a vantagem da objetividade, pois o fato por detrás dela, ou ato, está consubstanciado por farta documentação. Afinal, a forma está na própria documentação jurídica comprobatória de uma operação.

A essência econômica é uma das principais raízes que nutrem e sustentam toda a árvore contábil. Quando se souber entendê-la profundamente e aplicá-la com propriedade, se chegará, talvez, ao ponto mais alto da evolução contábil, no qual se saberá dosar relevância com objetividade ou subjetivismo responsável. Todas as áreas de avaliação são afetadas pela essência econômica em prevalência sobre a forma jurídica, como: contabilizações de "leasing" financeiro; e procedimentos de avaliação em incorporações, aquisições e fusões, bem como consolidações. Mas, indiretamente, se de fato houver mais importância à essência do que à forma, talvez sejam necessários esforços para avaliar o goodwill criado internamente, o capital intelectual e o valor da força de trabalho da empresa, no ativo. Isso mudaria radicalmente a composição do balanço e a própria função da Contabilidade, levando-a a procurar o "valor" e não o custo. Nesse sentido, a aplicação do conceito de Fair Value, embora sem os avanços conceituais antes citados, já se traduz numa faceta da prevalência da essência sobre a forma, mesmo que aplicado apenas nos ativos até agora considerados pela prática contábil. Embora essas avaliações “de valor da empresa" possam ser, subsidiariamente, assessoradas pelos contadores em demonstrações suplementares ou cálculos extra-contábeis, uma das raízes profundas que se analisará mais adiante, a terceira, não valida a inserção desses itens no balanço normal, na continuidade do empreendimento.

\section{PREVALÊNCIA DO TODO SOBRE O INDIVIDUAL: A SEGUNDA GRANDE RAIZ}

A teoria da Contabilidade, ao contrário do que se pensa mais corriqueiramente, repousa na visão de conjunto em prevalência sobre a análise individual dos componentes de um cenário contábil. É claro que, neste trabalho, quando se fala em prevalência disso em lugar daquilo, não significa que "aquilo" não tenha importância alguma e não deva ser considerado.

A Contabilidade, desde suas mais remotas origens, caracterizou-se como um campo de conhecimento a partir do qual seus intérpretes e formuladores, os contadores, fornecem informações sobre o quadro estático e dinâmico dos efeitos das relações de fatos e eventos, notadamente transações efetuadas entre a "entidade" e o "mundo exterior". Para esse mundo exterior (hoje extremamente multifacetado e complexo), o que de fato interessa é a visão da entidade "como um todo" em prevalência à visão das parcelas componentes. Essas parcelas são mais uma preocupação interna da entidade, nas aplicações da Contabilidade gerencial. É por isso que, tradicionalmente, a Contabilidade tem grande dificuldade em alocar resultados às várias divisões internas produtivas, o que dirá as de serviços.

A prevalência do "todo" sobre o "individual" é de grande relevância para a Teoria Contábil e, como consequiência, para a prática, pois condiciona uma série de princípios e procedimentos. Representa, mesmo, o âmago do substratum da Teoria Contábil. Vale 
qualquer que seja a entidade que estivermos contemplando. No âmbito de uma única entidade com divisões, até para análise da própria administração, o "todo" vem antes (tem prevalência) das suas divisões. Quando a entidade é a própria divisão (ou departamento, ou centro), os resultados dela têm prevalência sobre as análises individuais de seus componentes (investimentos, receitas e despesas individualmente considerados).

Finalmente, quando se trata de um conjunto de sociedades controladas por uma entidade-mãe a prevalência da análise recai sobre a pintura contábil do todo, ou seja, do conglomerado, com a devida separação do patrimônio da controladora dos interesses dos minoritários. Trata-se do famoso "balanço consolidado", como todos o conhecem. Insistese que a prevalência indica uma preferência e, na pior das hipóteses, uma ordem de precedência. Não se trata de desprezar o componente, mas de hierarquizar a análise e as conclusões sobre o todo.

Mesmo com relação à Contabilidade gerencial, os esforços e estudos para alocar resultados às divisões não têm sido, particularmente, bem sucedidos, a não ser que a descentralização seja tão acentuada que, de fato, as divisões possam escolher livremente entre adquirir fora ou receber de outra divisão interna os preços estabelecidos. Até no caso da autonomia total, tais práticas nem sempre levam o resultado máximo para a entidade, pelo simples motivo de que o resultado é obtido pela entidade "como um todo". Quando se utilizam, então, critérios baseados no "custo", as alocações são ainda mais imprecisas. Os estudos sobre esse assunto devem e podem continuar dentro da Contabilidade gerencial, mas com a aplicação de métodos quantitativos mais sofisticados. Surge a questão, todavia, de por em dúvida o fato de que só as divisões produtivas é que contribuem para o resultado global. $\mathrm{E}$ as de serviço? A entidade, como um todo, é responsável pelo resultado. Crê-se que, em lugar de tentar utilizar critérios arbitrários, o mais importante seria comparar o desempenho de cada divisão em relação às similares da concorrência, em função de indicadores de eficiência, produtividade e eficácia, deixando totalmente válida a segunda raiz, a prevalência do todo sobre o individual. De fato, têm decrescido bastante os estudos e as aplicações de preços de transferência, na realidade.

A raiz profunda "prevalência do todo sobre o individual" perpassa toda a teoria da Contabilidade e invade as práticas contábeis. Um exemplo mais convincente disso é que, nos EUA, até para fins tributários o "consolidado" é a entidade de preferência. Na contabilização de intangíveis, a maior parte é "não separável", ou seja, não pode ser alocada para outras finalidades e é de difícil avaliação. Quando se quer calcular o fluxo descontado de caixa dos ativos, não tem muito sentido fazê-lo para cada ativo, individualmente, mas para a entidade como um todo.

\section{PREVALÊNCIA DA ALOCAÇÃO SOBRE A VALORAÇÃO: A TERCEIRA GRANDE RAIZ}

A Contabilidade é, essencialmente, um modelo de alocação de recursos e não de avaliação. A accountability é sua característica fundamental. Em outras palavras, o objeto fundamental da Contabilidade é acompanhar a evolução do patrimônio através das quantias lançadas nas contas, frutos de transações e alocações de gastos. Essencialmente, a Contabilidade não visa que o patrimônio líquido represente o "valor econômico da entidade", o que envolveria a avaliação, na continuidade, dos intangíveis criados internamente, na versão mais simplificada. No máximo, poder-se-ia chegar, para o valor do patrimônio líquido, a um valor próximo do de mercado, (não das ações, mas valor de mercado dos ativos líquidos), após considerar todos os ativos identificáveis e subtrair os exigíveis. 
O surgimento das partidas dobradas favoreceu, sem dúvida, a preferência por valores de entrada para a avaliação dos ativos, mais conservadoramente valores históricos. Se a Contabilidade tivesse permanecido como na época dos inventários periódicos, talvez a forma de avaliação fosse algum valor corrente de mercado. A obtenção dos valores de mercado é possível recorrendo aos procedimentos preconizados por Edwards e Bell (1961) e ludícibus (1966 e 1968), mas obter-se-á, na melhor das hipóteses, um PL avaliado a valores de reposição que, para ser comparável com o do ano anterior, precisaria, ainda, do ajuste pela taxa de inflação do período.

A vocação da Contabilidade para não pretender avaliar o valor econômico da entidade é resultado, também, da função que suas informações representam para os tomadores de decisão, principalmente externos à entidade, que não querem ser privados de realizar suas avaliações sobre o valor da organização. Preferem, em lugar de um contador que thes dê sua versão, necessariamente subjetiva ao extremo, um profissional que thes forneça informações mais objetivas possíveis (embora nada seja totalmente objetivo nas demonstrações contábeis, exceto a data e o saldo de disponibilidades e de contas a pagar e a receber).

A Contabilidade é, antes de mais nada, um mecanismo de prestação de contas para a sociedade sobre os recursos que os sócios de uma entidade, em última análise, pessoas físicas, investiram e como foram administrados. Por isso, é um modelo do tipo "de onde vêm os recursos e no que foram aplicados".

Os usuários das informações contábeis, através das demonstrações contábeis, inclusive notas explicativas, com a utilização de outras fontes de informação, considerando-se que a análise dos dados é feita numa condição evolutiva, isto é, os indicadores contábeis são acompanhados no tempo, comparados com os de outras entidades etc., gostam, eles próprios, de estimar o valor econômico de uma entidade.

O contador não pode nem deve tomar o lugar dos tomadores de decisão. Podem, como profissionais, tentar avaliar da melhor forma possível todos os ativos e passivos identificáveis, até por algum tipo de valor que se aproxime do valor de mercado (fair value, talvez), mas sem a pretensão, na continuidade, de chegar a um patrimônio líquido que seja o valor econômico, ou mesmo o valor de mercado das ações.

Mesmo porque "valor" é algo extremamente subjetivo de ser entendido e cada agente tem uma noção diferente do que ele venha a ser em uma entidade.

Os parâmetros puramente contábeis, até mensurados pelo custo histórico, revelaram-se relevantes em vários estudos e pesquisas ligados à teoria positiva da Contabilidade, como nos de Beaver (1968) e na estrutura conceitual de Feltham e Ohlson (1995). Na verdade, indicadores como lucro contábil, lucro por ação e valor patrimonial da ação mostraram-se variáveis importantes para a predição de valores de mercado da ação e outras variáveis dependentes ligadas a esse mercado, tão ou mais direcionadores do que indicadores na moda, como EVA, EBITDA etc.

A prevalência da alocação sobre a valoração, terceira grande raiz da Teoria Contábil e, portanto da própria Contabilidade em sua aplicação prática, tem sido contestada nos últimos anos por economistas, autores sobre negócios, jornalistas e econômicos que não conhecem profundamente a Teoria Contábil, nem suas raízes históricas, bem como sua vocação íntima. Obviamente, na suposição de que se deveria perseguir o valor econômico ou de mercado do patrimônio líquido, sem se referir à raiz em si, pois, que se saiba, é a primeira vez que um autor assim a classifica.

Poderia parecer, à primeira vista, que essa terceira raiz contrariaria a primeira, "prevalência da essência sobre a forma", mas essa última refere-se a cada evento ou transação individualmente registrada na Contabilidade e não, propriamente, ao tipo de valoração à qual se queira chegar para o patrimônio líquido. 
Assim, enquanto não houver mudança radical no "terroir" sobre o qual se planta a árvore da teoria contábil, essa raiz permanecerá presente. Entretanto, como na produção dos vinhos, os contadores estão sempre à espreita de novas condições de solo, temperatura etc., a fim de melhorar a qualidade do produto.

\section{PREVALÊNCIA DA EVOLUÇÃO SOBRE O “STATUS QUO”: A QUARTA GRANDE RAIZ}

Existe essa quarta grande raiz que vivifica, nutre, modifica e até substitui algumas das outras, numa análise da evolução histórica da Contabilidade visualizada pelo que aconteceu através dos séculos.

Afinal, conforme Melis (1950) a Contabilidade acompanha a evolução da civilização humana em todas as suas etapas. Princípios e raízes (essas menos mutáveis do que aqueles) não são estáticos (também não mudam freqüentemente), mas se moldam à evolução das sociedades e das instituições jurídicas, econômicas e sociais.

Tivemos a fase pré-científica da Contabilidade, que nada mais era do que uma sequiência de inventários. Depois, com o advento das partidas dobradas, o entendimento da Contabilidade evoluiu, passando por várias fases, até atingir seu estado atual, que não está, todavia, totalmente estratificado. Há muitos movimentos evolutivos em ação, alguns na direção contrária a de outros, cujas resultantes ainda não estão discernidas claramente. Ao mesmo tempo em que se valoriza a subjetividade responsável do contador (no âmbito puramente conceitual), nota-se a interferência governamental (veja-se a SOX), restringindo essa liberdade de ação. Por outro lado, há uma pressão grande para a internacionalização das normas contábeis, outra forma indireta de restrição à capacidade de criação dos contadores (nem sempre dirigida para o bem, diga-se de passagem) em favor da comparabilidade, da redução de custos e da globalização econômica, objetivos importantíssimos.

Nem sempre a prevalência da essência sobre a forma foi uma grande raiz, pelo contrário, nos séculos passados e nas culturas jurídicas "Code-Law", predominou-se e ainda predomina-se a prevalência da forma sobre a essência.

Nem sempre a prevalência do todo sobre o individual foi tão realçada. Ao contrário, focava-se a análise mais nos componentes do que na resultante.

Talvez, nem sempre a prevalência da alocação sobre a valoração continuará válida. Como se viu, há várias forças, nem todas na mesma direção, fazendo evoluir, lentamente, mas, seguramente, a Contabilidade rumo ao futuro.

\footnotetext{
${ }^{1}$ Terroir - "Terroir (terroar) é uma palavra francesa sem tradução em nenhum outro idioma. Significa a relação mais íntima entre o solo e o micro-clima particular, que concebe o nascimento de um tipo de uva, que expressa livremente sua qualidade, tipicidade e identidade em um grande vinho, sem que ninguém consiga explicar 0 porquê." - Guide Larousse - France - Traduzido por Dr. Mário Brenno Pilleggi .
} 


\title{
CONSIDERAÇÕES FINAIS
}

As raízes profundas, no estágio atual da evolução, fornecem uma base sólida para entender melhor os princípios e a prática contábeis. O contador moderno, todavia, deve assumir a postura desafiadora de um viajante através do tempo, das civilizações e do espaço, na busca de novas terras e panoramas desconhecidos, ou analogamente, à descoberta do Novo Mundo que ainda nos trará muitas surpresas.

A Contabilidade evoluiu e continua a evoluir com sofreguidão, tentando estar sempre próxima às realidades econômica, institucional, jurídica e social das várias épocas, às vezes até antecipando-as; o que dificulta-nos chegar às certezas do que ela é ou poderá ser. Entender bem "o que ela faz" em cada etapa da evolução da sociedade e "porquê" (teoria positiva), já representa um importante passo à frente.

\section{REFERÊNCIAS}

BEAVER, W. The Information Content of annual earnings announcements. Journal of Accounting Research. v. 6, 1968. Suplemento.

CHAMBERS, R.J. Towards a general theory of accounting, 1961; The Australian society of accountants annual lecture.

EDWARDS, Edgar O.; BELL, Philip W. The Theory and measurement of business income; Berkeley and Los Angeles: University of California Press, 1961.

FELTHAM, G.; OHLSON ,J. Valuation and clear surplus accounting for operating and financial activities. Contemporary Accounting Research ,v.11, \#2 ,p. 689-731, 1995.

IUDÍCIBUS, Sérgio de. Contribuição à Teoria dos Ajustamentos Contábeis. Tese de Doutorado; FEA/USP, 1966.

Aspectos da Avaliação de Estoques a Preços Correntes. FEA/ USP, 1968.

MELIS, F. Storia della Ragioneria. Cesare Zuffi, Bologna, Itália, 1950.

PATON, W.A. Accounting Theory, 1922; reproduzido por Accounting Series Press, 1962, p. 16.

ROSS, Stephen A. The economic theory of agency: the principal's problem. The American Economic Review, v. 63, n. 2, may 1973, p. 134-139.

\section{ENDEREÇO DOS AUTORES}

\author{
Pontifícia Universidade Católica de São Paulo \\ Faculdade de Economia e Administração \\ Departamento de Contabilidade \\ Rua Monte Alegre, 984 - Perdizes \\ Sao Paulo, SP - Brasil \\ 05014-901
}

